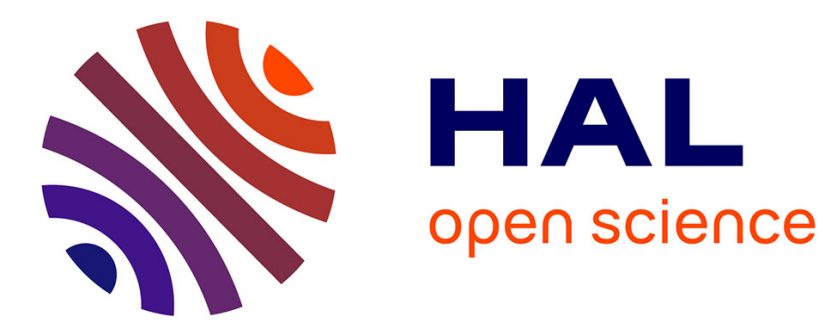

\title{
Hydrocarbons - Water Phase Equilibria Using the CPA Equation of State with a Group Contribution Method
}

Martha Hajiw, Antonin Chapoy, Christophe Coquelet

\section{To cite this version:}

Martha Hajiw, Antonin Chapoy, Christophe Coquelet. Hydrocarbons - Water Phase Equilibria Using the CPA Equation of State with a Group Contribution Method. Canadian Journal of Chemical Engineering, 2015, 93, pp.432-442. 10.1002/cjce.22093 . hal-01112045

HAL Id: hal-01112045

https://hal-mines-paristech.archives-ouvertes.fr/hal-01112045

Submitted on 7 Jan 2016

HAL is a multi-disciplinary open access archive for the deposit and dissemination of scientific research documents, whether they are published or not. The documents may come from teaching and research institutions in France or abroad, or from public or private research centers.
L'archive ouverte pluridisciplinaire HAL, est destinée au dépôt et à la diffusion de documents scientifiques de niveau recherche, publiés ou non, émanant des établissements d'enseignement et de recherche français ou étrangers, des laboratoires publics ou privés. 
Hydrocarbons - Water Phase Equilibria using the CPA Equation of State with a Group Contribution Method

Martha Hajiw ${ }^{\mathrm{a}, \mathrm{b}}$, Antonin Chapoy ${ }^{\mathrm{a},{ }^{*}}$, Christophe Coquelet ${ }^{\mathrm{b}, *}$

${ }^{a}$ Centre for Gas Hydrate Research, Institute of Petroleum Engineering, Heriot-Watt University, Edinburgh EH14 4AS, United Kingdom

${ }^{b}$ Mines Paristech, CTP - Centre Thermodynamique des procédés, 35 rue St Honoré 77305 Fontainebleau, France

It is proposed in this paper to extend the original group contribution method PPR78 to systems containing water, by combining it to the Cubic-Plus-Association (CPA) equation of state (EoS). Applying simple geometric combination rules, the binary interaction parameter $\mathrm{k}_{\mathrm{ij}}(\mathrm{T})$ can be calculated from interaction parameters between hydrocarbon groups and water. This model, called the GC-PR-CPA is applied to predict hydrocarbons - water mutual solubilities over a wide temperature and pressure range, depending on available literature data.

Group interaction parameters, here $\mathrm{CH}_{4}, \mathrm{C}_{2} \mathrm{H}_{6}, \mathrm{CH}_{3}, \mathrm{CH}_{2}, \mathrm{CH}, \mathrm{C}, \mathrm{CH}_{\text {aro }}, \mathrm{CH}_{2 \text {,cyclic }}, \mathrm{CH}_{\text {cyclic }} / \mathrm{C}_{\text {cyclic }}$, $\mathrm{C}_{2} \mathrm{H}_{4}, \mathrm{CH}_{2 \text {,alkene }} / \mathrm{CH}_{\text {alkene }}$ with $\mathrm{H}_{2} \mathrm{O}$ have been defined with solubility data. Predictions of the developed model have been validated against independent solubility data as well as water content in hydrocarbon rich phase. Predictions of the new model are in good agreement for light and medium hydrocarbons, however some deviations are observed for heavier hydrocarbons.

Keywords: Equation of state; Vapour - liquid equilibrium; Group contribution method; Binary interaction parameters

\footnotetext{
* Corresponding authors:

E-mail: antonin.chapoy@pet.hw.ac.uk Telephone: +44 (0) 1314513797.

E-mail: christophe.coquelet@mines-paristech.fr Telephone: +33 (0) 164694 962. Fax +33 (0) 164694968.
} 


\section{Introduction}

During production, transportation and processing, changes in temperature and pressure can lead to water condensation, ice and/or gas hydrates formation. Therefore accurate knowledge of mixtures phase equilibria are important for safe and economical design and operation of pipelines and production/processing facilities. Phase equilibria are predicted with thermodynamic models. Cubic equations of state (EoS), such as the Soave-Redlich-Kwong (SRK EoS) ${ }^{[1]}$ and the Peng-Robinson (PR $E o S)^{[2]}$ equations of state are widely used in the industry. Moreover, industry requires simple predictive models for phase diagram understanding and process design. However classical cubic EoS cannot handle correctly mixtures containing associating compounds, i.e. forming hydrogen bonding, such as water or alcohols. The Cubic-Plus-Association equation of state (CPA-EoS $)^{[3]}$ gives better predictions of such systems, according to Kontogeorgis et al. ${ }^{[3,4]}$. It combines a cubic EoS, usually the SRK EoS, and the Wertheim's term which describes the physical interactions between associating compounds. It is proposed in this work, to replace the SRK EoS with the PR EoS, and to use the PPR78 model developed by Jaubert and co-workers to quantify binary interactions between two hydrocarbon groups ${ }^{[5-9]}$. Although the PPR78 model was recently extended to aqueous systems ${ }^{[10]}$, a new temperature-dependent function is proposed in this study to predict the interactions between water and an hydrocarbon group. We indeed noticed that the addition of a Wertheim's term to the PR EoS was not compatible with the use of the existing group interaction parameters. The advantage of the PPR78 model is its simplicity and its computation time efficiency. Indeed, only component properties are needed: the critical pressure $\mathrm{P}_{C}$, the critical temperature $T_{C}$ and the acentric factor $\omega$. By combining the CPA EoS and the PPR78 model it is expected to have, in a simple way, better and physical reliable predictions for mixtures with water and alcohols. Thus it has been evaluated by predicting mutual solubilities of hydrocarbons - water and compared to the SRK-CPA EoS with adjusted binary interaction parameters or set to zero and two other SAFT type models: the GCA $\operatorname{EoS}^{[11]}$ and GC-PPC-SAFT EoS ${ }^{[12]}$.

\section{The GC-PR-CPA model}


Species forming hydrogen bonds (water, alcohols and glycols), also called associating compounds, present unusual thermodynamic behaviours, due to the strong attractive interactions between molecules. Classical equations of state combined with classical mixing rules are well known not to handle correctly the phase behaviour of mixtures containing water and/or alcohols. In this work the Cubic-Plus-Association (CPA) EoS, originally developed by Kontogeorgis and co-workers ${ }^{[3]}$, is used. In the original version this model combines the SRK cubic equation of state and the Wertheim's theory. In this work, the SRK equation of state is replaced by the Peng Robinson (PR) EoS ${ }^{[13]}$, justified by its better predictions of liquid densities and phase diagram in the critical region ${ }^{[14]}$. The binary interaction parameter calculated with the PPR78 EoS can be used with any other cubic EoS by using the mathematical relationship developed by Jaubert et al. which makes it possible to switch the binary interaction parameters from a cubic EoS to another one ${ }^{[15]}$.

\subsection{The PR-CPA pure compounds parameters}

The PR-CPA EoS is expressed here, in term of pressure for a pure compound (Eq. (1)):

$$
P=\frac{R T}{v-b_{i}}-\frac{a_{i}(T)}{v\left(v+b_{i}\right)+b_{i}\left(v-b_{i}\right)}-\frac{1}{2} \frac{R T}{v}\left(1+\rho \frac{\partial \ln (g)}{\partial \rho}\right) \sum_{i=1}^{N} x_{i} \sum_{A_{i}}\left(1-X_{A_{i}}\right)
$$

Parameters of the PR EoS are expressed below (Eq. (2)).

$$
\left\{\begin{array}{l}
\mathrm{R}=8.314472 \mathrm{~J} \cdot \mathrm{mol}^{-1} \cdot \mathrm{K}^{-1} \\
\eta_{c}=[1+\sqrt[3]{4-2 \sqrt{2}}+\sqrt[3]{4+2 \sqrt{2}}]^{-1} \approx 0.253076587 \\
b_{i}=\Omega_{b} \frac{R T_{C, i}}{P_{C, i}} \text { with } \Omega_{b}=\frac{\eta_{c}}{\eta_{c}+3} \approx 0.0777960739 \\
a_{i}(T)=a_{c, i}\left[1+C_{1, i}\left(1-\sqrt{\frac{T}{T_{C, i}}}\right)\right]^{2} \text { with } a_{c, i}=\Omega_{a} \frac{R^{2} T_{C, i}^{2}}{P_{C, i}} \text { and } \Omega_{a}=\frac{40 \eta_{c}+8}{49-37 \eta_{c}} \approx 0.457235529 \\
\text { If } \omega_{i} \leq 0.491 \text { then } C_{1, i}=0.37464+1.5422 \omega_{i}-0.26992 \omega_{i}^{2} \\
\text { If } \omega_{i}>0.491 \text { then } C_{1, i}=0.379642+1.48503 \omega_{i}-0.164423 \omega_{i}^{2}+0.016666 \omega_{i}^{3}
\end{array}\right.
$$

where $\mathrm{T}_{\mathrm{C}, \mathrm{i}}$ and $\mathrm{P}_{\mathrm{C}, \mathrm{i}}$ are respectively the critical temperature and the critical pressure of the component $i, \omega$ is the acentric factor, $a_{i}$ is the energy parameter and $b_{i}$ the co-volume. 
In the Wertheim's equation $\mathrm{g}(\mathrm{d})^{\mathrm{simpl}}$ (Eq. (3)) is the simplified expression of the radial distribution function as suggested by Kontogeorgis et al. ${ }^{[3]}, \eta$ the reduced fluid density, $\rho$ the molar density, $x$ is the mole fraction of the component $\mathrm{i}$ and $\mathrm{X}_{\mathrm{Ai}}$ the mole fraction of the molecule $\mathrm{i}$ not bonded at a site $\mathrm{A}$ (Eqs. (4) and (5)).

$g(d)^{\operatorname{sim} p}=\frac{1}{1-1.9 \eta}$ and $\eta=\frac{1}{4} b \rho=\frac{b}{4 v}$

$X^{A_{i}}=\frac{1}{1+\rho \sum_{j} n_{j} \sum_{B_{i}} X^{B_{i}} \Delta^{A_{i} B_{i}}}$

$\Delta^{A_{i} B_{i}}=g(d)^{\operatorname{simp}}\left[\exp \left(\frac{\varepsilon^{A_{i} B_{i}}}{R T}\right)-1\right] \beta^{A_{i} B_{i}} b$

Therefore, parameters $\mathrm{a}_{0, i}, \mathrm{~b}_{\mathrm{i}}, \mathrm{C}_{1, \mathrm{i}}$, the association energy $\varepsilon^{\mathrm{A}_{\mathrm{i}} \mathrm{B}_{\mathrm{i}}}$ and the association volume $\beta^{\mathrm{A}_{\mathrm{i}} \mathrm{B}_{\mathrm{i}}}$ are the five parameters of the CPA EoS. For non associating compounds, the three PR parameters are calculated with the critical temperature, critical pressure and acentric factor and $\varepsilon^{\mathrm{A}_{\mathrm{i}} \mathrm{B}_{\mathrm{i}}}$ and $\beta^{\mathrm{A}_{\mathrm{i}} \mathrm{B}_{\mathrm{i}}}$ are equal to zero. However, to improve predictions for associating compounds, these parameters have been fitted to vapour pressure and saturated liquid density data, using the objective function defined by Eq. (6). $X_{\mathrm{i}}$ is either the vapour pressure or the saturated liquid density and NEXP the number of experimental points:

$$
F=\frac{1}{N E X P} \sum_{i=1}^{N E X P}\left(\frac{X_{i, \text { exp }}-X_{i, \text { calc }}}{0.01 \times\left(1+X_{i, \text { exp }}\right)}\right)^{2}
$$

PR-CPA parameters for water are given in Table 1.

According to the terminology of Huang and Radosz ${ }^{[16]}$, the four-site (4C) association scheme has been applied for water.

\subsection{Mixing rules}

For mixtures, the equation parameters are defined with mixing rules. In this work, the classical mixing rule (van der Waals one fluid theory) has been applied for a(T) and b (Eqs. (7) and (8)).

$$
\begin{aligned}
& a(T)=\sum_{i=1}^{N} \sum_{j=1}^{N} x_{i} x_{j} \sqrt{a_{i}(T) a_{j}(T)}\left(1-k_{i j}\right) \\
& b=\sum_{i=1}^{N} z_{i} b_{i}
\end{aligned}
$$


where $\mathrm{N}$ is the number of components in the mixture.

Folas et al. ${ }^{[17]}$ mentioned that the combining rule CR1 ((Eqs. (9) and (10)) is one of the best mixing rules for the determination of $\varepsilon$ and $\beta$. CR1 is used in our GC-PR-CPA EoS.

$$
\begin{aligned}
\varepsilon^{A_{i} B_{j}} & =\frac{\varepsilon^{A_{i} B_{i}+\varepsilon^{A_{j} B_{j}}}}{2} \\
\beta^{A_{i} B_{j}} & =\sqrt{\beta^{A_{i} B_{i} \beta^{A_{j} B_{j}}}}
\end{aligned}
$$

\subsection{The group contribution method}

As seen in Eq. (7), the PR-CPA EoS applied for mixtures involves a binary interaction parameter $\mathrm{k}_{\mathrm{ij}}$. It is usually set to zero or defined by correlations specific to binary systems. In this work, $\mathrm{k}_{\mathrm{ij}}$ is calculated with the PPR78 model. Between 2004 and 2013, Jaubert and co-workers ${ }^{[5-10,18-25]}$ proposed a group contribution method and defined parameters of 21 groups to estimate temperature dependent Binary Interaction Parameters (Eqs. (11) and (12)) for mixtures involving hydrocarbons, water, mercaptans and permanent gases $\left(\mathrm{N}_{2}, \mathrm{CO}_{2}, \mathrm{H}_{2} \mathrm{~S}, \mathrm{H}_{2}\right)$.

$k_{i j}(T)=\frac{-\frac{1}{2} \times \operatorname{Sum}-\left(\frac{\sqrt{a_{i}(T)}}{b_{i}}-\frac{\sqrt{a_{j}(T)}}{b_{j}}\right)^{2}}{2 \frac{\sqrt{a_{i}(T) a_{j}(T)}}{b_{i} b_{j}}}$

with

$\operatorname{Sum}_{P P R 78}=\sum_{k=1}^{N g} \sum_{l=1}^{N g}\left(\alpha_{i k}-\alpha_{j k}\right)\left(\alpha_{i l}-\alpha_{j l}\right) A_{k l}\left(\frac{298.15}{T}\right)^{\left(\frac{B_{k l}}{A_{k l}}-1\right)}$

where $\mathrm{N}_{\mathrm{g}}$ is the number of groups, $\mathrm{k}$ and 1 are groups, $\mathrm{A}_{\mathrm{kl}}$ and $\mathrm{B}_{\mathrm{kl}}$ the interaction parameters between groups $\left(\mathrm{A}_{\mathrm{kl}}=\mathrm{A}_{\mathrm{lk}}\right.$ and $\left.\mathrm{B}_{\mathrm{kl}}=\mathrm{B}_{\mathrm{lk}}\right)$ and $\alpha_{\mathrm{ik}}$ is defined by Eq. (13):

$\alpha_{i k}=\frac{\text { number of group } k \text { in molecule } i}{\text { total number of groups in molecule } i}$

The group $\mathrm{H}_{2} \mathrm{O}$ has been added to the model. As shown in Figure 1, the binary interaction parameters, adjusted on literature data temperature by temperature, presents a polynomial tendency for hydrocarbons - water systems, similar to a Henry's law for such systems ${ }^{[26]}$. The trend of this 
parameter cannot be reproduced using Eq. (12). Therefore the term $\operatorname{Sum}_{P P R 78}$ has been modified for the group $\mathrm{H}_{2} \mathrm{O}$ with the introduction of three new interaction parameters $\mathrm{C}_{\mathrm{kH} 2 \mathrm{O}}, \mathrm{D}_{\mathrm{kH} 2 \mathrm{O}}$ and $\mathrm{E}_{\mathrm{kH} 2 \mathrm{O}}(\mathrm{Eq}$. 14). Table 2 presents $\mathrm{k}_{\mathrm{ij}}$ values for different temperatures between $283.15 \mathrm{~K}$ and $507.15 \mathrm{~K}$.

Sum $_{\text {asso }}=$

$\sum_{k=1}^{\mathrm{H}_{2} \mathrm{O}}\left(\alpha_{i k}-\alpha_{j k}\right)\left(\alpha_{i \mathrm{H}_{2} \mathrm{O}}-\alpha_{j \mathrm{H}_{2} \mathrm{O}}\right)\left(C_{k \mathrm{H}_{2} \mathrm{O}} T^{2}+D_{k \mathrm{H}_{2} \mathrm{O}} T+E_{k \mathrm{H}_{2} \mathrm{O}}\right)+\sum_{l=1}^{\mathrm{H}_{2} \mathrm{O}}\left(\alpha_{i \mathrm{H}_{2} \mathrm{O}}-\right.$

$\left.\alpha_{\mathrm{j}_{2} \mathrm{O}}\right)\left(\alpha_{i l}-\alpha_{j l}\right)\left(C_{\mathrm{H}_{2} \mathrm{Ol}} T^{2}+D_{\mathrm{H}_{2} \mathrm{Ol}} T+E_{\mathrm{H}_{2} \mathrm{Ol}}\right)$

With $\mathrm{C}_{\mathrm{k}, \mathrm{H} 2 \mathrm{O}}=\mathrm{C}_{\mathrm{H} 2 \mathrm{O}, 1}, \mathrm{D}_{\mathrm{k}, \mathrm{H} 2 \mathrm{O}}=\mathrm{D}_{\mathrm{H} 2 \mathrm{O}, 1}, \mathrm{E}_{\mathrm{k}, \mathrm{H} 2 \mathrm{O}}=\mathrm{E}_{\mathrm{H} 2 \mathrm{O}, \mathrm{l}}$.

The model proposed has therefore five parameters: two parameters $\left(A_{k l}\right.$ and $\left.B_{k l}\right)$ for non-associating groups and three parameters $\left(\mathrm{C}_{\mathrm{kl}}, \mathrm{D}_{\mathrm{kl}}\right.$ and $\left.\mathrm{E}_{\mathrm{kl}}\right)$ for associating groups such as water. Therefore, if a binary system without associating compounds is studied, e.g. ethane - propane, the model is reduced to the PPR78 EoS: the associating part of the PR-CPA EoS is not used and the binary interaction parameter is the one defined by Eqs. (11) and (12). However, for a system with water, e.g. methane water, the PR-CPA EoS is applied and the binary interaction parameter is calculated with Eq. (11) together with the new term $\operatorname{Sum}_{\text {asso }}$ (Eq. (14)).

In this work, the interaction parameters $\mathrm{C}_{\mathrm{kH} 2 \mathrm{O}}, \mathrm{D}_{\mathrm{kH} 2 \mathrm{O}}$ and $\mathrm{E}_{\mathrm{kH} 2 \mathrm{O}}$ are defined for $\mathrm{CH}_{4}, \mathrm{C}_{2} \mathrm{H}_{6}, \mathrm{CH}_{3}, \mathrm{CH}_{2}$, $\mathrm{CH}, \mathrm{C}, \mathrm{CH}_{\text {aro }}, \mathrm{CH}_{2, \text { cyclic }}, \mathrm{CH}_{\text {cyclic }} / \mathrm{C}_{\text {cyclic }}, \mathrm{C}_{2} \mathrm{H}_{4}, \mathrm{CH}_{2, \text { alkene }} / \mathrm{CH}_{\text {alkene }}$ groups in order to define $\mathrm{k}_{\mathrm{ij}}(\mathrm{T})$ for hydrocarbons-water mixtures. They have been calculated using a flash calculation, by minimizing the objective function defined in Eq. (15):

$$
F=\frac{1}{N E X P} \sum_{i=1}^{N E X P}\left(\frac{x_{i, \exp }-x_{i, c a l c}}{0.01 \times\left(1+x_{i, \exp }\right)}\right)^{2}
$$

where $N_{E X P}$ is the number of experimental data, $x_{i, \text { exp }}$ the experimental liquid mole fraction of hydrocarbon and $x_{i, c a l c}$ the calculated one. Table 3 presents the group interaction parameters obtained with Eq. (15). The objective function was limited to hydrocarbon solubility data, because they are more widely available in the literature. Indeed, in the case of VLE, measuring gas solubility is easier than measuring the water content ${ }^{[27]}$. Furthermore, the binary interaction parameter for systems with water has limited impact on water content predictions (see Figure 3). However, as shown on Figure 2, for the system methane - water, the SRK-CPA EoS with a $\mathrm{k}_{\mathrm{ij}}$ set to zero over predicts methane 
solubility, while the SRK-CPA EoS with adjusted binary parameters and the GC-PR-CPA EoS are in good agreement with experimental data. Therefore, adjusting the binary interaction parameter, using correlations or a group contribution method, improves solubility predictions.

\subsection{Validation of the model}

To evaluate the accuracy of the GC-PR-CPA model, solubilities of different hydrocarbons, such as normal alkanes, branched alkanes, aromatics naphthenics, and alkenes in water are compared to experimental data. The model has also been compared to the SRK-CPA EoS with adjusted binary interaction parameters or set to zero. Adjusted binary interaction parameters (BIP) for the SRK-CPA EoS are temperature dependent polynomial functions. They have been adjusted on VLE or LLE data and used directly from our software (Hydraflash ${ }^{\mathrm{TM}}{ }^{1}$ ) without any retuning for this work. When results were available, the model has been compared to two SAFT type models: the GCA EoS ${ }^{[11]}$ and the GCPPC-SAFT $\operatorname{EoS}^{[12]}$. As mentioned before, the GC-PR-CPA EoS has five parameters for pure associating compounds to be adjusted. These parameters are the same as those given by Kontogeorgis et al. in their paper ${ }^{[3]}$ for the SRK-CPA EoS. It is also the case for the SAFT EoS ${ }^{[28]}$ : the energy parameter, the segment diameter, the chain length parameter, the association energy and the association volume parameter are the five parameters to be adjusted for pure compounds as well as the binary interaction parameter for mixtures.

Furthermore, it is interesting to point out that heavier hydrocarbons, such as n-pentane, n-hexane, benzene, toluene and ethylbenzene present also a minimum of solubility in water. Tsonopoulos ${ }^{[29]}$ defined correlations for alkanes and aromatics solubility in water as well as the temperature corresponding to the minimum of solubility. In this paper, the ability of the GC-PR-CPA model to reproduce the minimum of solubility is evaluated for aromatics. The model is compared to the original correlation defined by Tsonopoulos (Eqs. (16) and (17)) and to the modified correlation with readjusted parameters $\mathcal{A}, \mathcal{B}$ and $\mathcal{C}$.

$\ln \left(x_{i}\right)=\mathcal{A}_{i}+\frac{\mathcal{B}_{i}}{T}+\mathcal{C}_{i} \ln (T)$

\footnotetext{
${ }^{1}$ http://www.hydrafact.com/
} 
$T_{\min }=\frac{\mathcal{B}_{i}}{\mathcal{C}_{i}}$

Finally, in process simulation, EoS are not only used to determine phase diagram but must be able to correctly estimate thermodynamic properties like densities, enthalpies or estimate Henry's law constant $^{[26]}$ at infinite dilution. As an example, the capability of the GC-PR-CPA EoS to predict the mixing enthalpy $\mathrm{h}^{\mathrm{M}}$ is evaluated here for the benzene-water system.

\subsection{Database}

Several solubility data have been found for lighter alkanes and aromatics with water. Comparison between data has been made, and data which did not follow the major trend of other experimental data have been deleted. Smoothed data for methane ${ }^{[30]}$ and ethane ${ }^{[31]}$, and data covering the larger range of temperature and pressure have been used for calculations. The model has been validated with other VLE and/or LLE data, if available. There are fewer data for branched alkanes and naphthenics, but the same process has been applied to screen the data. Finally for heavier components ( $n$-decane and heavier), very few data are existing, but their accuracy is not proved, since their solubility in water is very small (lower than $1.10^{-9}$ ). In literature, the uncertainty on experimental data is estimated to be between $3 \%$ and $5 \%$ for lighter hydrocarbons, and up to $16 \%$ for alkanes greater than $\mathrm{C}_{9}$.

\section{Results and discussion}

\subsection{Methane - water}

Group parameters $\mathrm{C}_{\mathrm{CH} 4, \mathrm{H} 2 \mathrm{O}}, \mathrm{D}_{\mathrm{CH} 4, \mathrm{H} 2 \mathrm{O}}$ and $\mathrm{E}_{\mathrm{CH} 4, \mathrm{H} 2 \mathrm{O}}$ for the binary system methane - water have been calculated with smoothed solubility data ${ }^{[30]}$ for temperatures from 283.15 to $423.15 \mathrm{~K}$ and up to 200 MPa. Figure 2 shows the methane solubility in water for three isotherms. The AAD (Average Absolute Deviation) for each isotherm $(473.15 \mathrm{~K}, 423.15 \mathrm{~K}$, and 310.93$)$ are $4 \%, 2 \%$ and $2 \%$, respectively.

For smoothed data used in calculations, the AAD is $3 \%$ and the Average Absolute Error AAE is 8.2.10 ${ }^{-5}$. Thus, with error on experimental data between $3 \%$ and $5 \%$, it can be concluded that the 
model GC-PR-CPA reproduced with accuracy the methane solubility in water. And, as shown on Figure 3, the water solubility in the methane rich vapour phase is also well reproduced.

\subsection{Ethane - water}

In their paper, Mao and co-workers ${ }^{[31]}$ presented ethane solubility data in water for temperatures from 273.15 to $473.15 \mathrm{~K}$ and pressures up to $100 \mathrm{MPa}$, with an experimental uncertainty of $7 \%$. Parameters $\mathrm{C}_{\mathrm{C} 2 \mathrm{H} 6, \mathrm{H} 2 \mathrm{O}}, \mathrm{D}_{\mathrm{C} 2 \mathrm{H} 6, \mathrm{H} 2 \mathrm{O}}$ and $\mathrm{E}_{\mathrm{C} 2 \mathrm{H} 6, \mathrm{H} 2 \mathrm{O}}$ have been defined with these smoothed data As seen on Figure 4, the model reproduces the ethane solubility in water, with reasonable accuracy (the AAD is $3 \%$ and the AAE 3.9.10 $0^{-5}$ ). Moreover compared to the two other predictive models (Figure 5), the GC-PR-CPA EoS follows the experimental trend with temperature as well as the GCA $\operatorname{EoS}^{[11]}\left(7.7 \%\right.$ and $6 \%$ deviations respectively). The GC-PPC-SAFT ${ }^{[12]}$ presents the highest deviation with $25 \%$, even if dipole-dipole interactions are taken into account in this equation. Despite the deviations at high pressures, inherent to the CPA EoS, the model is in good agreement with the experimental data. The deviation at higher pressures could be attributed to the neglect of "crossassociation" between ethane and water.

\subsection{Other alkanes with water}

- Phase equilibrium predictions

Parameters have been obtained using experimental data for the following binary systems: VLE data for propane - water $^{[32]}$ and $n$-butane - water ${ }^{[33]}$, LLE data for $n$-hexane - water ${ }^{[34]}$ and $n$-nonane water $^{[35]}$. For lighter compounds, such as propane, predictions are in good agreement with experimental data, as shown on Figure 6 and Figure 7. The AAD on all data for propane is $12 \%$ and the average of the AAE is $1.7 .10^{-5}$ (the maximum being 1.4.10-4). The GC-PR-CPA EoS is better than the GC-PPC-SAFT model (22\% deviation) but presents deviations with experimental data (4\% deviation against $7 \%$ for the GCA EoS). The SRK-CPA EoS with adjusted $\mathrm{k}_{\mathrm{ij}}$ is the closest to experimental data with $2 \%$ of deviation. As a group contribution method, the GC-PR-CPA EoS looks to predict with higher accuracy than the SAFT type EoS. Propane solubility is better predicted with the GC-PR-CPA EoS at temperatures higher than $320 \mathrm{~K}$. 
$N$-hexane solubility is given on Figure 8. The AAD for all data is $15 \%$ and the AAE is $6.7 .10^{-7}$ (the maximum being $5 \cdot 0.10^{-6}$ ). As seen on Figure 9, the GC-PR-CPA model is better than the two other models, with $14 \%$ deviation against $20 \%$. The SRK-CPA EoS presents $15 \%$ for these data. For other alkanes up to $n$-heptane, the AAD is lower than $20 \%$. For these binary systems, the model is accurate and represents the minimum of solubility, but it shows some discrepancies at high temperatures.

Due to a lack of data and because of the uncertainty of experimental data, predictions are poor for all alkanes from $n$-decane to eicosane. It should be pointed out the solubility of heavy alkanes is extremely small, i.e. lower than $1.10^{-9}$. Therefore, it is very difficult to represent their behaviour.

- Discussions

As seen on Figure 5, Figure 7 and Figure 9, other SAFT group contribution models do not reproduce alkanes behaviour in water as well as the CPA EoS (SRK-CPA or GC-PR-CPA). Referring to two studies of Privat et al. ${ }^{[36]}$ and Polishuk et al. ${ }^{[37]}$ on SAFT EoS, inconsistent predictions for pure compounds were highlighted: they have shown that a SAFT type equation of state, in their paper the PC-SAFT EoS, predicts two fluid-fluid saturation curves, two critical points and a LLV triple point ${ }^{[36]}$. Moreover, some combinations of fitted SAFT parameters seem to lead to unrealistic phase behaviour at temperatures and pressures of industrial processes. It is thus mandatory to implement a specific algorithm to avoid these problems. These phenomena are not observed with the GC-PR-CPA EoS and the model is accurate at ambient conditions and even at low temperatures. The binary interaction parameters being adjusted for the binary system propane-water and being temperature dependent, it is evident that the SRK-CPA EoS gives better predictions. But it is interesting to see that the GC-PRCPA EoS is more accurate than what is expected for a group contribution method.

\subsection{Results for branched alkanes}

Group interaction parameters $\mathrm{C}_{\mathrm{CH}, \mathrm{H} 2 \mathrm{O}}, \mathrm{D}_{\mathrm{CH}, \mathrm{H} 2 \mathrm{O}}, \mathrm{E}_{\mathrm{CH}, \mathrm{H} 2 \mathrm{O}}$ have been determined by combining solubility data of $i$-butane, $i$-propane and 2,3-dimethylbutane and $\mathrm{C}_{\mathrm{C}, \mathrm{H} 2 \mathrm{O}}, \mathrm{D}_{\mathrm{C}, \mathrm{H} 2 \mathrm{O}}, \mathrm{E}_{\mathrm{C}, \mathrm{H} 2 \mathrm{O}}$ with 2,2dimethylpropane, 2,2-dimethylbutane, 2,2-dimethylpentane and 3,3-dimethylpentane. Limited data are available for the solubility of branched alkanes in water and generally can only be found at 0.1 MPa. So, considering the scarcity of data, higher deviations should be expected. The model represents 
well $i$-butane solubility in water at $0.1 \mathrm{MPa}$ ( $5 \%$ deviation). It gives the right behaviour but over predicts $i$-pentane solubility: the AAD is $22 \%$ and the AAE is $3.1 .10^{-6}$ (the maximum being $4.6 .10^{-6}$ ). Results for 2,2-dimethylpropane, 2,2-dimethylbutane and 2,2-dimethylpentane are given in Table 4. Predictions for 2,3-dimethylbutane ${ }^{[34]}$ and 3,3-dimethylpentane ${ }^{[38]}$ are shown on Figure 10, the AAD being respectively $10 \%\left(\mathrm{AAE}=9 \cdot 0.10^{-7}\right)$ and $11 \%\left(\mathrm{AAE}=3 \cdot 3 \cdot 10^{-7}\right)$. Binary interaction parameters have been adjusted for the SRK-CPA EoS for 2,3-dimethylbutane but not for 3,3-dimethylpentane (Figure 10), explaining why the $\mathrm{k}_{\mathrm{ij}}$ is equal to zero and why the SRK-CPA gives $8 \%$ deviation for 2,3dimethylbutane but 79\% for 3,3-dimethylpentane. Regarding to predictions, the low solubility values and the quantity of data available, the model can be considered accurate for these binary systems.

\subsection{Results for naphthenics}

Limited data are available for cyclic components with water. Only cyclohexane-water and methylcyclohexane-water binary systems present reliable data. As seen on Figure 11, the behaviour is well represented for cyclohexane and methylcyclohexane at $0.1 \mathrm{MPa}$. The AAD are respectively $8 \%$ and $19.5 \%$ and the AAE 2.1.10 $0^{-6}$ and $1.1 .10^{-6}$. In comparison, the SRK-CPA EoS with adjusted binary interaction parameters presents $9.5 \%$ deviation for cyclohexane and $7 \%$ for methylcyclohexane. Predictions for cyclohexane are similar for both models, but the group contribution method degrades slightly the results. But considering the small values of solubilities, the model can be considered accurate for these binary systems.

\subsection{Results for alkenes}

Ethylene is a group in the PPR78 model. Parameters for $\mathrm{C}_{2} \mathrm{H}_{4}$ group with water have been adjusted with VLE data. Four isotherms $(308.15 \mathrm{~K}, 310.93 \mathrm{~K}, 327.59 \mathrm{~K}$, and $348.15 \mathrm{~K})$ are presented on Figure 12 and Figure 13. The AAD are respectively $1 \%, 4 \%, 8 \%$ and $2 \%$. For all data, the AAD is less than $7 \%$ and the AAE is about $6.8 .10^{-5}$. The SRK-CPA EoS presents $8 \%$ deviations for ethylene solubility. Considering both models, they are similar, with better predictions at higher pressures for the GC-PR-CPA EoS. Therefore, it can be considered that the model GC-PR-CPA represents with good accuracy the ethylene solubility in water. 
Parameters for the group $\mathrm{CH}_{2, \text { alkene }} / \mathrm{CH}_{\text {alkene }}$ have been defined using VLE data for propylene. Figure 14 shows propylene solubility for two isotherms, $310.93 \mathrm{~K}$ and $377.59 \mathrm{~K}$. The AAD are respectively 4 $\%$ and $6 \%$, and $8 \%$ for all data. The AAE for propylene solubility is $3 \cdot 3 \cdot 10^{-5}$. Both GC-PR-CPA and SRK-CPA EoS represent well the propylene solubility in water, with a small advantage for the SRKCPA EoS. Water content data in propylene have also been found in the literature. Results are given on Figure 15 for two isotherms as well. The AAD for all data is $27 \%$ and the AAE 5.7.10 ${ }^{-3}$. Water content values vary from $3.65 .10^{-3}$ to $2.59 .10^{-1}$. As seen on Figure 15, the model does not represent water content as well as the propylene solubility, but it gives the right shape, contrary to the SRKCPA EoS which has only $7.5 \%$ deviation with experimental data. Higher deviations for the GC-PRCPA EoS could be explained by the interactions between all groups present. Here, for propylene, only parameters for $\mathrm{CH}_{2, \text { alk }} / \mathrm{CH}_{\text {alk }}$ with $\mathrm{H}_{2} \mathrm{O}$ and $\mathrm{CH}_{3}$ with $\mathrm{H}_{2} \mathrm{O}$ are determined. But there are also interactions between $\mathrm{CH}_{2 \text {,alk }} / \mathrm{CH}_{\text {alk }}$ and $\mathrm{CH}_{3}$ and it can affect predictions. Indeed, referring to the paper on alkenes by Jaubert et al. ${ }^{[8]}$, both liquid and vapour phases could not be accurately predicted some for alkene-alkane systems and it could therefore explain deviations in water content predictions.

\subsection{Results for aromatics}

- Phase equilibrium predictions

To define the group interaction parameter for aromatics, the interaction between the group $\mathrm{CH}_{\text {aro }}$ and water has been considered. Thus, parameters $\mathrm{C}_{\mathrm{CHaro}, \mathrm{H} 2 \mathrm{O}}, \mathrm{D}_{\mathrm{CHaro}, \mathrm{H} 2 \mathrm{O}}$ and $\mathrm{E}_{\mathrm{CHaro}, \mathrm{H} 2 \mathrm{O}}$ have been calculated using liquid-liquid equilibrium data for benzene - water. Data available in the literature are mostly given at $0.1 \mathrm{MPa}$. So parameters obtained give good benzene solubility in water at this pressure (Figure 16). The AAD for these data is $2 \%$ and the AAE is $7.5 .10^{-6}$. Data have also been measured for pressures from 0.5 to $10 \mathrm{MPa}$ for a Gas Processors Association project ${ }^{[39]}$ and the AAD is $5 \%$ and the AAE 3.7.10 ${ }^{-5}$. These results show the good accuracy of the model for this system. However, the model under predicts water solubility in the hydrocarbon phase (Figure 17), with $43 \%$ deviation at atmospheric pressure.

Groups $\mathrm{C}_{\mathrm{Haro}}$ and $\mathrm{C}_{\text {aro }}$ are present in toluene, ethylbenzene and xylenes. After defining $\mathrm{C}_{\mathrm{CHaro}, \mathrm{H} 2 \mathrm{O}}$, $\mathrm{D}_{\mathrm{CHaro}, \mathrm{H} 2 \mathrm{O}}$ and $\mathrm{E}_{\mathrm{CHaro}, \mathrm{H} 2 \mathrm{O}}$, it is possible to adjust these three parameters for $\mathrm{C}_{\mathrm{aro}}-\mathrm{H}_{2} \mathrm{O}$ with liquid-liquid 
equilibrium data. Deviations for toluene (Figure 18) and ethylbenzene (Figure 19) are respectively 9 $\%$ and $10 \%$ on all data, and the AAE $1 \cdot 0 \cdot 10^{-5}$ and $3.4 \cdot 10^{-6}$. For data presented on figures 18 and 19 , the AAD are lower with $0.9 \%$ and $7 \%$ deviations respectively. There are more discrepancies for xylenes $(11 \%$ for $m$-xylene and $p$-xylene and $40 \%$ for $o$-xylene of deviations and the AAE are between $3 \cdot 6 \cdot 10^{-6}$ and $1.2 .10^{-5}$ ) but the minimum of solubility is always represented. Higher deviations for o-xylene are explained by the scatter in the experimental data: no agreement between references is observed.

Therefore, the GC-CPA-PR model can represent aromatics solubilities in water at $0.1 \mathrm{MPa}$, but it under predicts water solubility in hydrocarbon liquid phase.

- Minimum of solubility

Using the experimental data presented on Figure 16, Figure 18 and Figure 19, parameters $\mathcal{A}, \mathcal{B}$ and $\mathcal{C}$ from Tsonopoulos correlation (Eq. (16) have been readjusted for benzene, toluene and ethylbenzene. The temperature of minimum of solubility has been calculated for the GC-PR-CPA model and using Eq. (17) with readjusted parameters $\mathcal{B}$ and $\mathcal{C}$. Predictions have been compared to experimental data (Figure 16, Figure 18 and Figure 19) and to the original correlation published by Tsonopoulos. All parameters are given in Table 5. The AAD between experimental data and the readjusted correlation are $1.5 \%$ for benzene, $3 \%$ for toluene and $2.5 \%$ for ethylbenzene. In their paper, Bohon and Claussen $^{[40]}$ define the minimum of solubility near $291.15 \mathrm{~K}$ for all liquid hydrocarbons studied: benzene, toluene, ethylbenzene, $m$-xylene, $p$-xylene, biphenyl and naphtalene. As for Tsonopoulos ${ }^{[29]}$, the temperature of the minimum of solubility is $291 \mathrm{~K}$, but according to Tsonopoulos and Wilson ${ }^{[41]}$ the minimum of solubility for benzene is $283.74 \mathrm{~K}$. Referring to Table 5, temperatures of minimum of solubility, calculated with the readjusted correlation present some discrepancies with their value. The temperature of the minimum of solubility has also been calculated for the GC-PR-CPA EoS, being 285.69 K for benzene, 288.91 K for toluene and 294 K for ethylbenzene. The calculated minimum of solubility of benzene is closer to the one presented by Tsonopoulos and Wilson ${ }^{[41]}$ than the one by Bohon and Claussen ${ }^{[40]}$ or Tsonopoulos ${ }^{[29]}$. The difference in the values could be explained by the experimental data used for parameters adjustment. To show the importance of temperature dependency, a constant BIP has been adjusted on solubility data for the SRK-CPA EoS for the system 
benzene-water. As seen on Figure 16, the SRK-CPA EoS with a constant BIP does not predict a minimum of solubility and predictions are far from experimental data.

- Mixing enthalpy

Mixing enthalpies, as defined by Privat and Jaubert ${ }^{[42]}$, were calculated for the binary system benzene - water and compared to experimental data at $592 \mathrm{~K}$ and $16.4 \mathrm{MPa}^{[43]}$, measured by Wormald and Slater and mistakenly called excess enthalpies. As seen on Figure 20, the mixing enthalpy behaviour is well reproduced by both the SRK-CPA and GC-PR-CPA EoS and it has to be pointed out that the BIPs have not been adjusted using enthalpy data. The SRK-CPA EoS slightly under predicts the mixing enthalpies, while the GC-PR-CPA EoS under predicts only for a water mole fraction between 0.6 and 0.86. At $592 \mathrm{~K}$ and $16.4 \mathrm{MPa}$, the maximum experimental value is $13.7 \mathrm{~kJ}^{\mathrm{mol}}{ }^{-1}$. The SRKCPA EoS predicts a slightly lower value of $12.5 \mathrm{~kJ}^{\mathrm{m} \mathrm{mol}^{-1}}$ and the GC-PR-CPA EoS $13.1 \mathrm{~kJ} \cdot \mathrm{mol}^{-1}$. The maximum absolute deviation is $3.0 \mathrm{~kJ}^{\mathrm{mol}}{ }^{-1}$ for the SRK-CPA EoS and $1.2 \mathrm{~kJ} \cdot \mathrm{mol}^{-1}$ for the GC-PRCPA EoS. To improve the predictions, interaction parameters can also be adjusted on mixing enthalpies data.

\section{Conclusion}

A model combining the PR-CPA EoS and a group contribution method has been developed. To be extended to systems with water, the original equation defining $k_{i j}(T)$ has been modified. Three new group interaction parameters had to be defined between groups already existing and the last group $\mathrm{H}_{2} \mathrm{O}$. In general, the model gives accurate predictions for lighter alkanes (lower than $n$-decane) and gives the right behaviour for heavier compounds. Considering the low solubility values for heavy alkanes, it is difficult to have correct predictions. It can also predict other hydrocarbons solubilities such as aromatics, naphthenics and alkenes with a good representation of the minimum of solubility, and properties of mixing, such as the enthalpy. The GC-PR-CPA EoS does not degrade predictions as much as it would be expected from a group contribution method, but it is in general slightly less accurate than the SRK-CPA EoS with adjusted binary interaction parameters. 


\section{Acknowledgments}

This work was funded by Chevron, GDF-Suez, Petrobras, Statoil and Total, whose support is gratefully acknowledged.

The authors would like to acknowledge also Dr Eric Auger for the utilisation of the GC-PPC-SAFT. Martha Hajiw would like to thank Heriot Watt University for the use of Hydraflash ${ }^{\mathrm{TM}}$ and the funding.

\section{List of symbols}

temperature dependent energy term in the PR term (MPa. $\left.\mathrm{L}^{2} \cdot \mathrm{mol}^{-2}\right)$

$\mathrm{a}_{0} \quad$ parameter in the energy term $\left(\mathrm{MPa} \cdot \mathrm{L}^{2} \cdot \mathrm{mol}^{-2}\right)$

$\mathrm{A}_{\mathrm{i}} \quad$ site $\mathrm{A}$ in the molecule $\mathrm{i}$

$\mathrm{A}_{\mathrm{kl}}, \mathrm{B}_{\mathrm{kl}} \quad$ constant parameters in the PPR78 expression of binary interaction parameters

b co-volume parameter

$\mathrm{C}_{\mathrm{kl}}, \mathrm{D}_{\mathrm{kl}}, \mathrm{E}_{\mathrm{kl}} \quad$ constant parameters in the GC-PR-CPA expression of binary interaction parameters

F objective function

g radial distribution function

$\mathrm{h}^{\mathrm{M}} \quad$ mixing enthalpy

$\mathrm{k}_{\mathrm{ij}}(\mathrm{T}) \quad$ temperature dependent binary interaction parameter

$\mathrm{P} \quad$ pressure $(\mathrm{MPa})$

$\mathrm{P}_{\mathrm{c}} \quad$ critical pressure $(\mathrm{MPa})$

T temperature $(\mathrm{K})$

$\mathrm{T}_{\mathrm{c}} \quad$ critical temperature $(\mathrm{K})$

v molar volume (L.mol $\left.{ }^{-1}\right)$

$\mathrm{x} \quad$ liquid molar fraction

y vapour molar fraction

Greek letters

$\beta \quad$ association volume parameter 
$\Delta$

$\varepsilon$

$\kappa$

$\rho$

Subscripts

calc

$\exp$

$\mathrm{i}, \mathrm{j}$

$\mathrm{k}, 1$

$\mathrm{R}$

w

List of abbreviations

critical

groups

water
AAD

AAE

CPA

CR

EoS

GCA

GC-PR-CPA

GC-PPC-SAFT

LLE

PPR78

PR

SAFT

SRK association strength

association energy parameter (MPa.L.mol ${ }^{-1}$ )

parameter in the energy term

molar density

calculated

experimental

molecule

reduced 


\section{References}

[1] G. Soave, Chemical Engineering Science 1972, 27, 1197-\&.

[2] W. Abdoul, E. Rauzy, A. Peneloux, Fluid Phase Equilibria 1991, 68, 47-102r.

[3] G. M. Kontogeorgis, M. L. Michelsen, G. K. Folas, S. Derawi, N. von Solms, E. H. Stenby, Industrial \& Engineering Chemistry Research 2006, 45, 4855-4868.

[4] G. M. Kontogeorgis, M. L. Michelsen, G. K. Folas, S. Derawi, N. von Solms, E. H. Stenby, Industrial \& Engineering Chemistry Research 2006, 45, 4869-4878 10.1021/ie051306n.

[5] J. N. Jaubert, S. Vitu, F. Mutelet, J. P. Corriou, Fluid Phase Equilibria 2005, 237, 193-211.

[6] S. Vitu, J. N. Jaubert, F. Mutelet, Fluid Phase Equilibria 2006, 243, 9-28.

[7] J.-N. Jaubert, R. Privat, F. Mutelet, Aiche Journal 2010, 56, 3225-3235.

[8] J.-W. Qian, J.-N. Jaubert, R. Privat, Fluid Phase Equilibria 2013, 354, 212-235.

[9] J. N. Jaubert, F. Mutelet, Fluid Phase Equilibria 2004, 224, 285-304.

[10] J.-W. Qian, R. Privat, J.-N. Jaubert, Industrial \& Engineering Chemistry Research 2013, 52, 16457 16490.

[11] S. Pereda, J. A. Awan, A. H. Mohammadi, A. Valtz, C. Coquelet, E. A. Brignole, D. Richon, Fluid Phase Equilibria 2009, 275, 52-59.

[12] S. Tamouza, J. P. Passarello, P. Tobaly, J. C. de Hemptinne, Fluid Phase Equilibria 2004, 222, 6776

[13] D. Peng, D. B. Robinson, Industrial \& Engineering Chemistry Fundamentals 1976, 15, 59-64.

[14] M. Atilhan, S. Aparicio, K. R. Hall, Industrial \& Engineering Chemistry Research 2012, 51, 96879699.

[15] J. N. Jaubert, R. Privat, Fluid Phase Equilibria 2010, 295, 26-37.

[16] S. H. Huang, M. Radosz, Industrial \& Engineering Chemistry Research 1990, 29, 2284-2294.

[17] G. K. Folas, G. M. Kontogeorgis, M. L. Michelsen, E. H. Stenby, Industrial \& Engineering Chemistry Research 2006, 45, 1527-1538.

[18] R. Privat, F. Mutelet, J. N. Jaubert, Industrial \& Engineering Chemistry Research 2008, 47, 10041 10052.

[19] R. Privat, J. N. Jaubert, F. Mutelet, Industrial \& Engineering Chemistry Research 2008, 47, 20332048.

[20] R. Privat, J. N. Jaubert, F. Mutelet, Journal of Chemical Thermodynamics 2008, 40, 1331-1341.

[21] R. Privat, J.-N. Jaubert, Fluid Phase Equilibria 2012, 334, 197-203.

[22] J.-W. Qian, R. Privat, J.-N. Jaubert, P. Duchet-Suchaux, Energy \& Fuels 2013, 27, 7150-7178.

[23] J.-W. Qian, J.-N. Jaubert, R. Privat, Journal of Supercritical Fluids 2013, 75, 58-71.

[24] S. Vitu, R. Privat, J.-N. Jaubert, F. Mutelet, Journal of Supercritical Fluids 2008, 45, 1-26.

[25] F. Mutelet, S. Vitu, R. Privat, J. N. Jaubert, Fluid Phase Equilibria 2005, 238, 157-168.

[26] A. H. Harvey, Aiche Journal 1996, 42, 1491-1494.

[27] H. Haghighi, A. Chapoy, B. Tohidi, Oil \& Gas Science and Technology-Revue D Ifp Energies Nouvelles 2009, 64, 141-154.

[28] N.-H. Dong, J.-C. de Hemptinne, R. Lugo, J.-P. Passarello, P. Tobaly, Industrial \& Engineering Chemistry Research 2011, 50, 7467-7483.

[29] C. Tsonopoulos, Fluid Phase Equilibria 1999, 156, 21-33.

[30] Z. Duan, S. Mao, Geochimica Et Cosmochimica Acta 2006, 70, 3369-3386.

[31] S. D. Mao, Z. G. Zhang, J. W. Hu, R. Sun, Z. H. Duan, Fluid Phase Equilibria 2005, 238, 77-86.

[32] A. Azarnoosh, J. J. McKetta, Petroleum Refiner. 1958, 37, 275-278.

[33] H. H. Reamer, B. H. Sage, W. N. Lacey, Industrial \& Engineering Chemistry 1952, 44, 609-615. 
[34] A. Maczynski, D. G. Shaw, M. Goral, B. Wisniewska-Goclowska, A. Skrzecz, I. Owczarek, K. Blazej, M. C. Haulait-Pirson, G. T. Hefter, F. Kapuku, Z. Maczynska, C. L. Young, Journal of Physical and Chemical Reference Data 2005, 34, 709-753.

[35] D. G. Shaw, A. Maczynski, M. Goral, B. Wisniewska-Goclowska, A. Skrzecz, I. Owczarek, K. Blazej, M. C. Haulait-Pirson, G. T. Hefter, F. Kapuku, Z. Maczynska, A. Szafranski, Journal of Physical and Chemical Reference Data 2005, 34, 2299-2345.

[36] R. Privat, R. Gani, J.-N. Jaubert, Fluid Phase Equilibria 2010, 295, 76-92.

[37] I. Polishuk, R. Privat, J.-N. Jaubert, Industrial \& Engineering Chemistry Research 2013, 52, 1387513885.

[38] L. C. Price, The American Association of Petroleum Geologists bulletin 1976, 60, 213-244.

[39] A. Valtz, P. Guilbot, D. Richon, in Book Amine BTEX Solubility, Ecole des Mines de Paris, 2002.

[40] R. L. Bohon, W. F. Claussen, Journal of the American Chemical Society 1951, 73, 1571-1578.

[41] C. Tsonopoulos, G. M. Wilson, Aiche Journal 1983, 29, 990-999.

[42] R. Privat, J.-N. Jaubert, Chemical Engineering Science 2012, 82, 319-333.

[43] C. J. Wormald, J. Slater, Journal of Chemical Thermodynamics 1996, 28, 627-636.

[44] R. G. Sultanov, V. G. Skripka, A. Y. Namiot, Zhurnal Fizicheskoi Khimii 1972, 46, 2160-\&.

[45] O. L. Culberson, and McKetta, J.J., Jr., Petrol. Trans. AIME 1951, 223-298.

[46] F. Tabasinejad, R. G. Moore, S. A. Mehta, K. C. Van Fraassen, Y. Barzin, Industrial \& Engineering Chemistry Research 2011, 50, 4029-4041.

[47] P. C. Gillespie, Wilson, G.M., in Book Vapor liquid and liquid liquid equilibria: methane-water; water-carbon - dioxide; water-hydrogen sulphide;water-npentane; water-methane - npentane, GPA RR48, 1982.

[48] S. Mokraoui, C. Coquelet, A. Valtz, P. E. Hegel, D. Richon, Industrial \& Engineering Chemistry Research 2007, 46, 9257-9262.

[49] A. Azarnoosh, McKetta,J.J, Petroleum Refiner. 1958, 37, 275-278.

[50] J. C. De Hemptinne, H. Delepine, C. Jose, J. Jose, Revue De L Institut Francais Du Petrole 1998, 53, 409-419.

[51] C. Marche, H. Delepine, C. Ferronato, J. Jose, Journal of Chemical and Engineering Data 2003, 48, 398-401.

[52] A. Maczynski, D. G. Shaw, M. Goral, B. Wisniewska-Goclowska, A. Skrzecz, I. Owczarek, K. Blazej, M. C. Haulait-Pirson, G. T. Hefter, F. Kapuku, Z. Maczynska, A. Szafranski, C. L. Young, Journal of Physical and Chemical Reference Data 2005, 34, 1399-1487.

[53] J. E. Davis, J. J. McKetta, J. Chem. Eng. Data 1960, 5, 374-375.

[54] E. J. Bradbury, D. McNulty, R. L. Savage, E. E. McSweeney, Ind. Eng. Chem. 1952, 44, 211-212.

[55] A. Azarnoosh, J. J. McKetta, J. Chem. Eng. Data 1959, 4, 211-212.

[56] C. C. Li, J. J. McKetta, J. Chem. Eng. Data 1963, 8, 271-275.

[57] D. M. Alexander, Journal of Physical Chemistry 1959, 63, 1021-1022.

[58] A. Maczynski, D. G. Shaw, M. Goral, B. Wisniewska-Goclowska, A. Skrzecz, I. Owczarek, K. Blazej, M. C. Haulait-Pirson, G. T. Hefter, Z. Maczynska, A. Szafranski, C. Tsonopoulos, C. L. Young, Journal of Physical and Chemical Reference Data 2005, 34, 477-552.

[59] E. Groschuff, Zeitschrift Fur Elektrochemie Und Angewandte Physikalische Chemie 1911, 17, 348354.

[60] A. E. Hill, Journal of the American Chemical Society 1923, 45, 1143-1155.

[61] C. McAuliffe, Journal of Physical Chemistry 1966, 70, 1267-1275.

[62] J. Polak, B. C. Y. Lu, Canadian Journal of Chemistry-Revue Canadienne De Chimie 1973, 51, 40184023. 